\title{
Prognostic role of B7-H4 in patients with non-small cell lung cancer: A meta-analysis
}

\author{
Zhibo Tan ${ }^{1}$, Weixi Shen ${ }^{1}$ \\ ${ }^{1}$ Department of Oncology, Shenzhen Hospital of Southern Medical University, Shenzhen, Guangdong, P.R. China \\ Correspondence to: Weixi Shen, email: shenweixiszh@sohu.com \\ Keywords: meta-analysis, B7-H4, lung cancer, evidence-based medicine \\ Received: December 14, $2016 \quad$ Accepted: January 24, $2017 \quad$ Published: February 23, 2017 \\ Copyright: Tan et al. This is an open-access article distributed under the terms of the Creative Commons Attribution License \\ (CC-BY), which permits unrestricted use, distribution, and reproduction in any medium, provided the original author and source \\ are credited.
}

\section{ABSTRACT}

B7 homolog 4 (B7-H4) has been recently reported to be a prognostic marker in non-small cell lung cancer (NSCLC) in some studies. However, the results remained conflicting. Thus, we aimed to comprehensively assess the association between B7-H4 expression and prognosis of NSCLC patients by performing a meta-analysis. Relevant publications were thoroughly searched of PubMed, Embase, Web of Science and China National Knowledge Infrastructure (CNKI). The pooled odds ratios (ORs) and hazard ratios (HRs) with $95 \%$ confidence intervals (CIs) were applied to evaluate the effects. A total of 9 studies comprising 1444 patients were included in this meta-analysis. B7-H4 overexpression was associated with presence of lymph node metastasis ( $O R=3.59,95 \% C I=2.39-5.38, p<0.001$; fixed effect), advanced TNM stage $(\mathrm{OR}=2.36,95 \% \mathrm{CI}=1.2-4.67, \mathrm{p}=0.013$; random effect), and poor differentiation (OR=2.11, 95\%CI=1.12-3.99, $p=0.021$; fixed effect). However, B7-H4 had no significant correlation with gender, age or histology in NSCLC. Furthermore, in a fixed effects model, the results indicated that B7-H4 overexpression was significantly associated with poor OS $(\mathrm{HR}=2.03,95 \% \mathrm{CI}=1.41-2.92, \mathrm{p}<0.001)$. This meta-analysis demonstrated that high B7-H4 expression is an unfavorable prognostic factor in NSCLC. Because few studies were included for meta-analysis and almost all included studies were performed on Chinese patients, therefore; large scale prospective studies are needed to verify our results.

\section{INTRODUCTION}

Lung cancer is the most commonly diagnosed cancer around the world [1]. The prognosis of lung cancer is also poor, and the overall 5 year survival is about $15 \%$ over the past decades [2]. Non-small cell lung cancer (NSCLC), accounting for approximately $80 \%-85 \%$ of all lung cancer cases, is the main form of lung cancer [3]. More than half of NSCLC patients are in advanced stages (stage IIIB/ IV) at first diagnosis, leading to a poor prognosis [2]. Despite several prognostic markers including performance status (PS), age and weight loss have been identified for prognostication. The predicative accuracy is still unsatisfactory [4]. Obviously, more reliable prognostic markers are needed to make the management of NSCLC be more individualized.
Immune escape is recognized as an important characteristic of cancer cells [5]. B7 homolog 4 (B7-H4, $\mathrm{B} 7 \mathrm{~S} 1, \mathrm{~B} 7 \mathrm{x}$ ) is a member of the B7 family. Members of the B7 family are involved in immune escape of tumor cells, since the level of activation of the anti-tumor immune response depends on the balance between co-stimulatory and co-inhibitory signals [6]. B7-H4 shares about 25\% amino acid homology with other B7 family members including B7-H1 (PD-L1), B7-DC (PD-L2) and B7-H3 [7, 8]. B7-H4 palys a pivotal role in the regulation of tumor microenvironment. Evidence shows that B7-H4 could act as a co-inhibitor of T-cell response and innate immunity [9, 10]. B7-H4 expression was also investigated as a potential prognostic marker in a variety of solid tumors including osteosarcoma, NSCLC, oral squamous cell carcinoma, hepatocellular carcinoma, gastric cancer and glioma 
[11-18]. A number of studies have explored the prognostic significance of B7-H4 in NSCLC [16-27], whereas the results were controversial. Li et al. reported that in NSCLC patients with brain metastases, patients with high B7-H4 expression survived shorter than patients with low B7-H4 expression $(p=0.002)[23]$. Furthermore, Wang and colleagues also reported that B7-H4 serum level was an independent prognostic indicator of overall survival (OS) and progression-free survival (PFS) $(\mathrm{p}<0.01)[26]$. However, Xu et al. showed that B7-H4 expression was not significantly associated with OS in NSCLC $(p=0.32)$ [22]. Therefore, we performed a meta-analysis of published data to more precisely assess the impact of B7-H4 on prognosis of NSCLC.

\section{RESULTS}

\section{Studies selection and characteristics}

One hundred and eight potentially relevant records were obtained after initial search (Figure 1). After duplicates were excluded, 81 records were screened by title and/ or abstract and 57 records were subsequently removed. A total of 24 studies were evaluated for eligibility by fulltext screening. Then, 15 studies were excluded due to the following reasons: insufficient data $(n=11)$, meeting abstracts $(\mathrm{n}=3)$, and duplicate studies $(\mathrm{n}=1)$. Finally, 9 eligible studies [16-18, 22-27] were included for meta-analysis. The flow diagram shows the literature selection process (Figure 1). The main characteristics of the 9 included studies were shown in Table 1. The total sample was 1444, ranging from 49 to 552 patients per study. Eight studies [16-18, 22-24, $26,27]$ were conducted in China and one study [25] was performed in USA. Five studies [16, 23, 25-27] were in English and 4 studies [17, 18, 22, 24] were in Chinese. All studies were assigned with NOS scores more than 6 .

\section{Correlation of B7-H4 with clinicopathological parameters}

The main results showing the association of B7H4 with clinicalpathological factors were summarized in Table 2 and Figure 2. Six studies [16-18, 22, 24, 27]

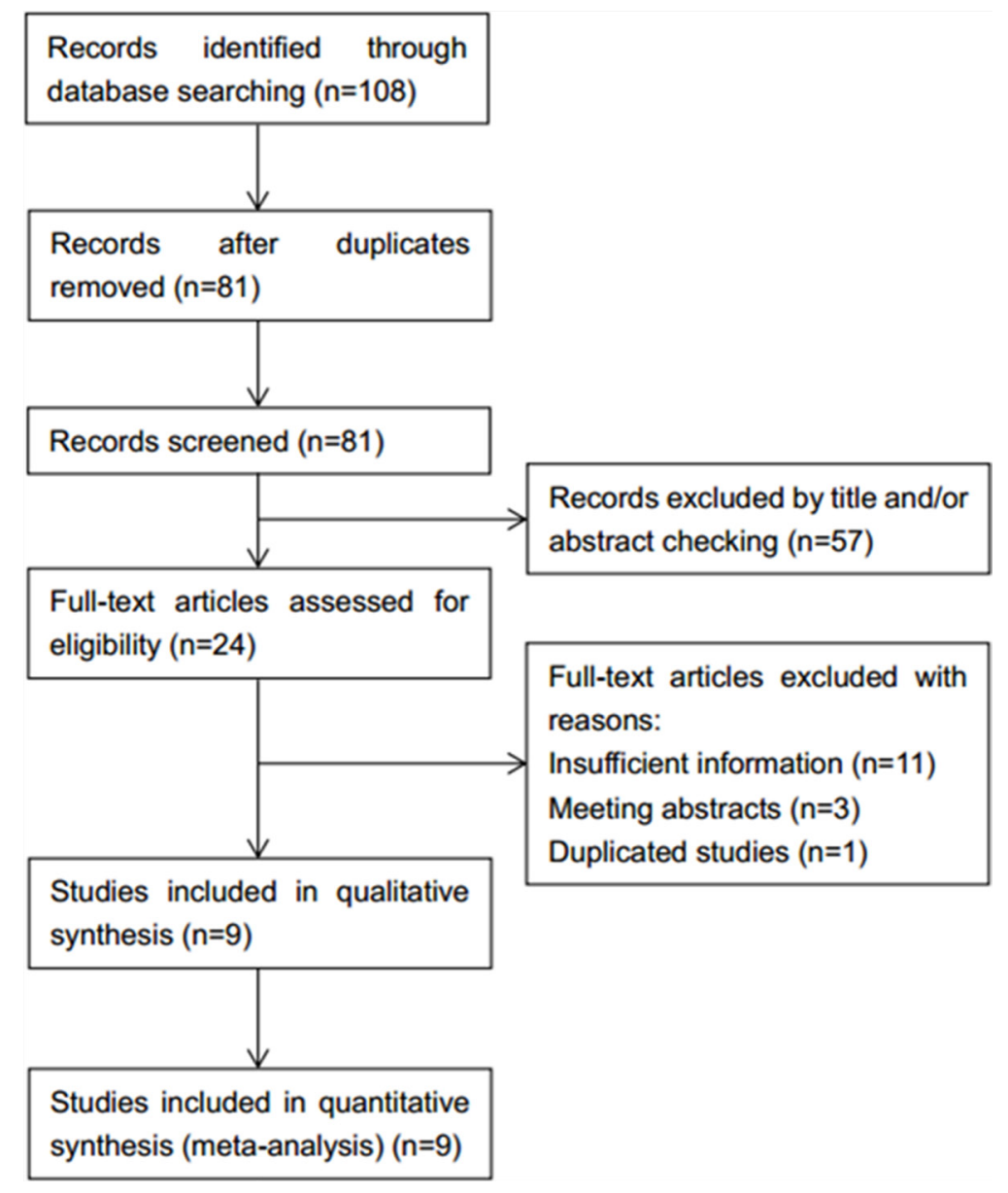

Figure 1: Flow diagram of the inclusion and exclusion of studies. 
Table 1: Main characteristic of included studies

\begin{tabular}{lcccccccc}
\hline First author & Year & $\begin{array}{c}\text { NOS } \\
\text { score }\end{array}$ & Country & Sample size & Gender (M/F) & $\begin{array}{c}\text { Female } \\
(\%)\end{array}$ & $\begin{array}{c}\text { Detection } \\
\text { method }\end{array}$ & Tumor stage \\
\hline Sun [16] & 2006 & 7 & China & 70 & $49 / 21$ & 30 & IHC & I-III \\
Zhang [17] & 2009 & 6 & China & 52 & $30 / 22$ & 42.3 & IHC & I-IV \\
Qin [18] & 2010 & 7 & China & 80 & $52 / 28$ & 35 & IHC & I-III \\
Xu [22] & 2011 & 7 & China & 103 & $67 / 36$ & 35 & IHC & I-IV \\
Li [23] & 2013 & 7 & China & 49 & $37 / 12$ & 24.5 & IHC & IV \\
Liu [24] & 2015 & 6 & China & 94 & $44 / 50$ & 53.2 & IHC & NR \\
Schalper [25] & 2016 & 7 & USA & 552 & $316 / 236$ & 42.8 & QIF & I-IV \\
Wang [26] & 2016 & 8 & China & 316 & $160 / 156$ & 49.4 & ELISA & I-IV \\
Xu [27] & 2016 & 7 & China & 128 & $80 / 48$ & 37.5 & ELISA & I-IV \\
\hline
\end{tabular}

Abbreviations: IHC: immunohistochemistry; QIF: quantitative immunofluorescence; ELISA: enzyme linked immunosorbent assay; NR: not reported.

Table 2: Association between B7-H4 and clinicalpathological factors in NSCLC

\begin{tabular}{lccccccc}
\hline Variables & $\begin{array}{c}\text { No. of } \\
\text { studies }\end{array}$ & $\begin{array}{c}\text { No. of } \\
\text { patients }\end{array}$ & Effects model & OR (95\%CI) & p & \multicolumn{2}{c}{ Heterogeneity } \\
\cline { 6 - 8 } & $\left.\boldsymbol{I}_{\mathbf{2}} \mathbf{\%}\right)$ & $\mathbf{P}_{\mathbf{h}}$ \\
\hline Gender (male vs female) & 8 & 1,128 & Fixed & $0.94(0.68-1.29)$ & 0.699 & 0 & 0.65 \\
Age ( $\geq 60$ vs $<60$, years) & 7 & 576 & Fixed & $0.92(0.65-1.29)$ & 0.617 & 0 & 0.827 \\
$\begin{array}{l}\text { Histology (SCC vs } \\
\text { ADC) }\end{array}$ & 7 & 1,034 & Random & $2.35(0.77-2.36)$ & 0.289 & 60.3 & 0.019 \\
$\begin{array}{l}\text { Lymph node metastasis } \\
\text { (yes vs no) }\end{array}$ & 6 & 527 & Fixed & $3.59(2.39-5.38)$ & $<0.001$ & 26.5 & 0.235 \\
$\begin{array}{l}\text { TNM stage (III+IV vs } \\
\text { I+II) }\end{array}$ & 4 & 830 & Random & $2.36(1.2-4.67)$ & 0.013 & 54.6 & 0.086 \\
$\begin{array}{l}\text { Differentiation (poor vs } \\
\text { moderate/well) }\end{array}$ & 4 & 347 & Fixed & $2.11(1.12-3.99)$ & 0.021 & 0 & 0.583 \\
\hline
\end{tabular}

Abbreviations: SCC: Squamous cell carcinoma; ADC: Adenocarcinoma.

reported the correlation between $\mathrm{B} 7-\mathrm{H} 4$ and lymph node metastasis. The pooled data were: $\mathrm{OR}=3.59$, $95 \% \mathrm{CI}=2.39-5.38, \mathrm{p}<0.001$, (fixed effect) suggesting that B7-H4 overexpression was associated with presence of lymph node metastasis in NSCLC. In addition, pooled data from 4 studies [16, 18, 25, 27] also suggested high B7-H4 expression was correlated with advanced TNM stage $(\mathrm{OR}=2.36,95 \% \mathrm{CI}=1.2-4.67, \mathrm{p}=0.013$; random effect). Four studies $[16,18,22,24]$ reported the data on differentiation, the pooled results $(\mathrm{OR}=2.11,95 \% \mathrm{CI}=1.12$ 3.99, $\mathrm{p}=0.021$; fixed effect) showed that $\mathrm{B} 7-\mathrm{H} 4$ expression was also associated with poor differentiation. However, the pooled data from 8 studies [16-18, 22-25, 27], 7 studies [16-18, 22-24, 27] and 7 studies [16-18, 22, 23, 25, 27] suggested that there was no significant association of B7-H4 with gender, age or histology in NSCLC (Table 2, Figure 2).

\section{Impact of B7-H4 expression on OS of NSCLC}

The HRs for OS were available in 3 studies [22, 23, $26]$ involving 468 patients. As the heterogeneity among studies was not significant $\left(I=29.3 \%, \mathrm{P}_{\mathrm{h}}=0.243\right)$, the fixed effects model was used (Figure 3 ). The pooled HR showed a significant correlation of B7-H4 with shorter OS $(\mathrm{HR}=2.03,95 \% \mathrm{CI}=1.41-2.92, \mathrm{p}<0.001$; Figure 3$)$. 


\section{Publication bias}

Publication bias was tested using Begg's funnel plot in this meta-analysis. As shown in Figure 4, the funnel plot was symmetrical and showed no evidence of publication bias (Begg's $\mathrm{p}=0.602$ ).

\section{DISCUSSION}

To our knowledge, this is the first meta-analysis on the relationship between B7-H4 expression and clinicalpathological features and OS in NSCLC patients. By aggregating data from 9 studies with 1444 patients, we showed that elevated B7-H4 expression was significantly associated with presence of lymph node metastasis, advanced TNM stage, poor differentiation and shorter OS in NSCLC. Taken together, these results suggested that B7-H4 could act as a potential prognostic factor for NSCLC patients.

B7-H4 is a new member of B7 family which was identified in 2003 [28]. B7-H4 had a profound inhibitory effect on development and function of T cells [28]. Recent

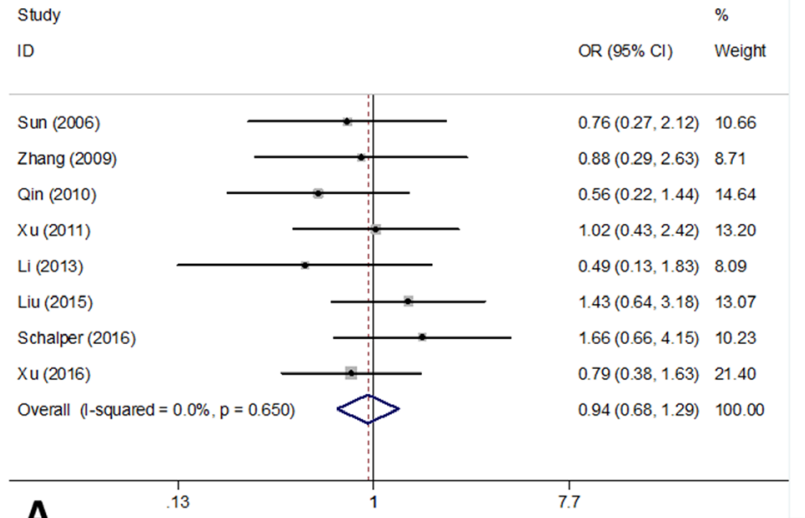

A

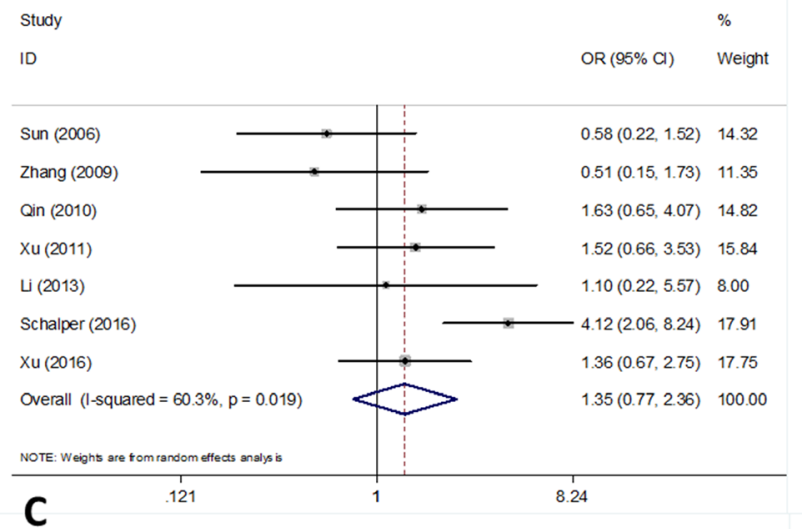

Study

ID

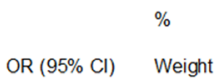

Study

OR $(95 \% \mathrm{Cl}) \quad$ Weight

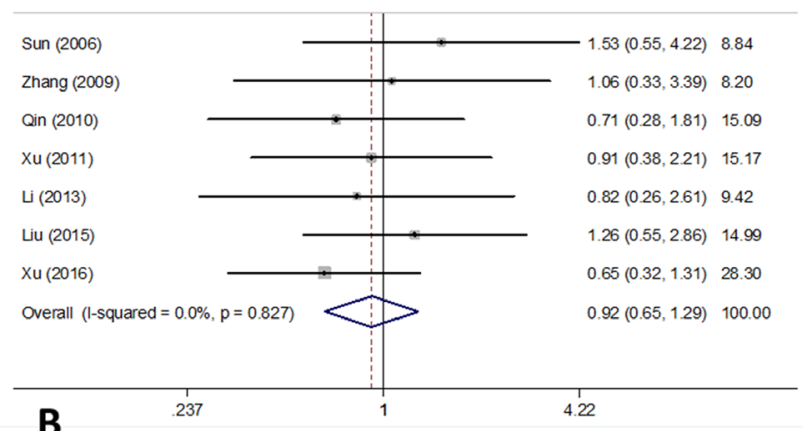

B
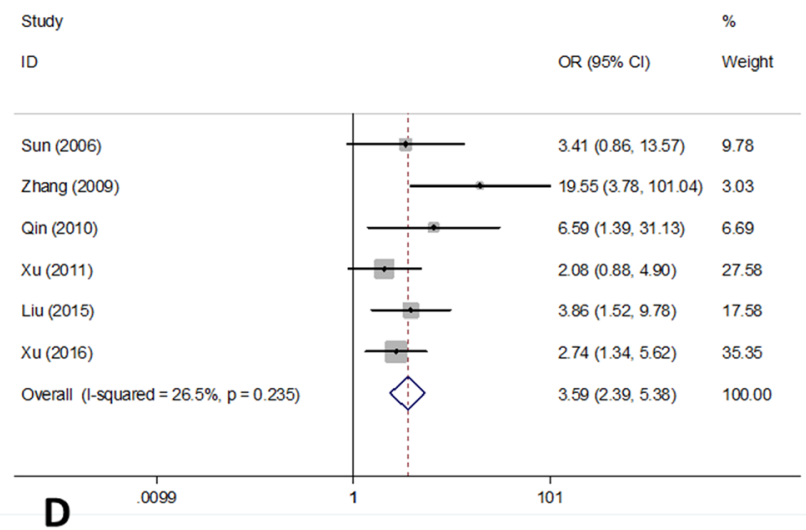

Study $\quad \%$

ID OR $(95 \% \mathrm{Cl}) \quad$ Weight

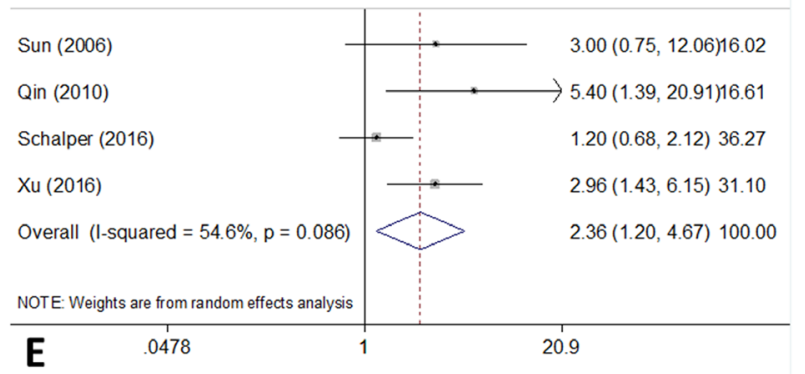

Figure 2: Forest plots of OR for the relation between B7-H4 expression and (A) gender; (B) age; (C) histology; (D) lymph node metastasis; (E) TNM stage and (F) differentiation. 
investigations also showed that $\mathrm{B} 7-\mathrm{H} 4$ overexpression could promote the proliferation of FOXP3+ regulatory $T$ cells (Tregs) and the secretion of IL-10 and TGF- $\beta 1$ [29]. B7-H4 was also found to be correlated with Tregs infiltration and thus facilitate the immune tolerance in tumor microenvironment [30]. There is also evidence showing that B7-H4 suppresses the function of antigen presenting cells (APCs). Kryczek et al demonstrate that Treg cells trigger high levels of IL-10 production by APCs, stimulate APC B7-H4 expression, and render
APCs immunosuppressive [31]. B7-H4 was found to be expressed in various cancers, including gastric cancer [15, 32], renal cell carcinoma [33], pancreatic cancer [34] and prostate cancer [35]. Studies also suggested that B7-H4 was a prognostic indicator of poor survival and different clinicalpathological features in various cancers $[32,34$, $35]$.

We found that several studies [36-38] had investigated the correlation between B7-H4 and prognosis of cancer patients using meta-analysis. Song et al
Study

ID
$\%$

ES $(95 \% \mathrm{Cl}) \quad$ Weight

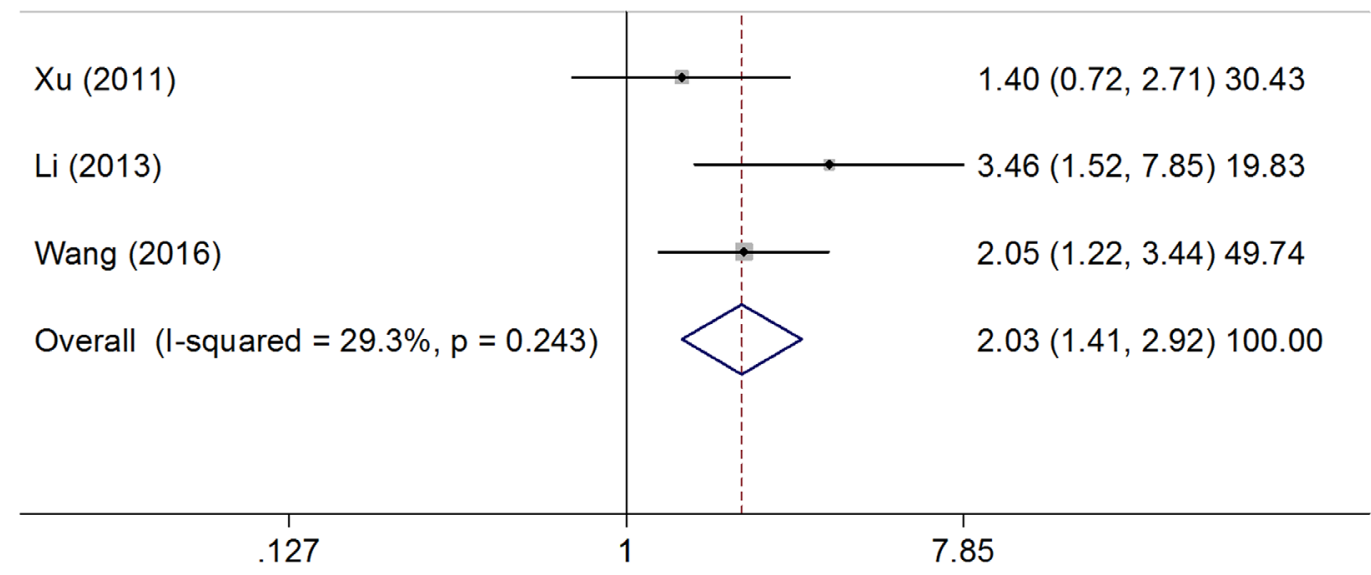

Figure 3: Forest plot for the association of B7-H4 expression with overall survival.

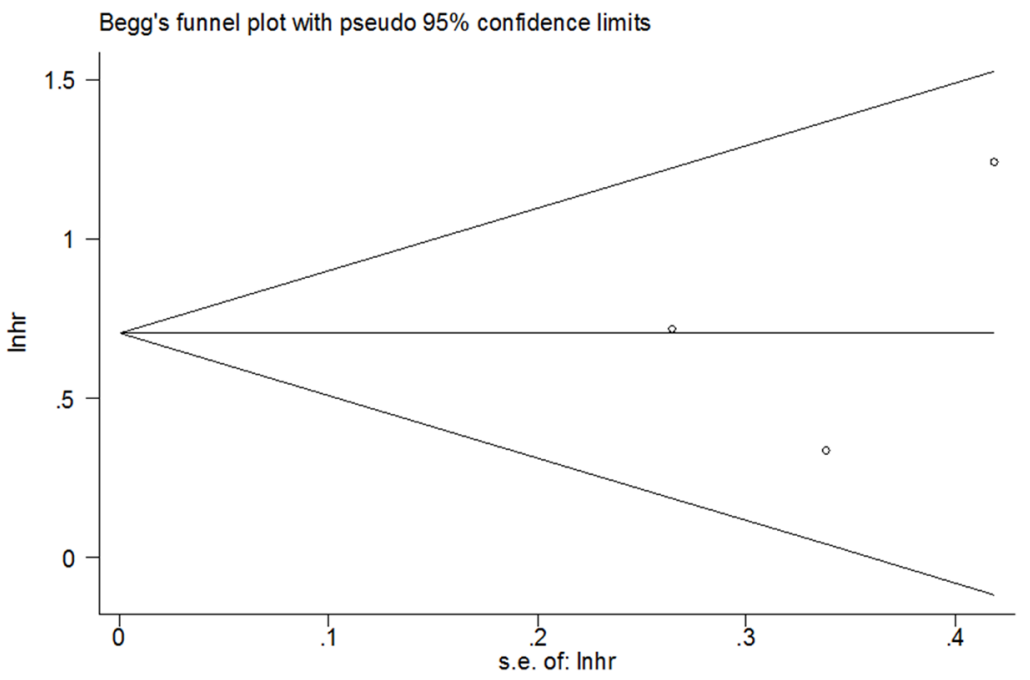

Figure 4: Funnel plot for publication bias assessment. 
Table 3: Quality assessment of the included studies according to the Newcastle-Ottawa scale

\begin{tabular}{|c|c|c|c|c|c|c|c|c|c|}
\hline \multirow[b]{2}{*}{ Studies } & \multicolumn{4}{|c|}{ Selection ( 4 stars in total, 1 for each item) } & \multirow[b]{2}{*}{$\begin{array}{l}\text { Comparability } \\
\text { (2 stars) }\end{array}$} & \multicolumn{3}{|c|}{$\begin{array}{c}\text { Outcome (3 stars in total, } 1 \text { for each } \\
\text { item) }\end{array}$} & \multirow[b]{2}{*}{$\begin{array}{l}\text { Total } \\
\text { score }\end{array}$} \\
\hline & $\begin{array}{c}\text { Representativeness } \\
\text { of the exposed } \\
\text { cohort }\end{array}$ & $\begin{array}{l}\text { Selection } \\
\text { of the } \\
\text { nonexposed } \\
\text { cohort }\end{array}$ & $\begin{array}{l}\text { Assessment } \\
\text { of exposure }\end{array}$ & $\begin{array}{c}\text { Outcome } \\
\text { not } \\
\text { present } \\
\text { at start } \\
\text { of study }\end{array}$ & & $\begin{array}{l}\text { Assessment } \\
\text { of outcome }\end{array}$ & $\begin{array}{l}\text { Follow- } \\
\text { up long } \\
\text { enough } \\
\text { for } \\
\text { outcomes }\end{array}$ & $\begin{array}{l}\text { Adequacy } \\
\text { of follow- } \\
\text { up }\end{array}$ & \\
\hline Sun [16] & 1 & 1 & 1 & 1 & 2 & 1 & 0 & 0 & 7 \\
\hline $\begin{array}{l}\text { Zhang } \\
{[17]}\end{array}$ & 1 & 1 & 1 & 1 & 2 & 0 & 0 & 0 & 6 \\
\hline Qin [18] & 1 & 1 & 1 & 1 & 2 & 1 & 0 & 0 & 7 \\
\hline $\mathrm{Xu}[22]$ & 1 & 1 & 1 & 1 & 1 & 1 & 1 & 0 & 7 \\
\hline $\mathrm{Li}[23]$ & 1 & 1 & 1 & 1 & 1 & 1 & 1 & 0 & 7 \\
\hline Liu [24] & 1 & 1 & 1 & 1 & 1 & 1 & 0 & 0 & 6 \\
\hline $\begin{array}{l}\text { Schalper } \\
{[25]}\end{array}$ & 1 & 1 & 1 & 1 & 2 & 1 & 0 & 0 & 7 \\
\hline $\begin{array}{l}\text { Wang } \\
{[26]}\end{array}$ & 1 & 1 & 1 & 1 & 1 & 1 & 1 & 1 & 8 \\
\hline $\mathrm{Xu}$ [27] & 1 & 1 & 1 & 1 & 2 & 1 & 0 & 0 & 7 \\
\hline
\end{tabular}

combined data from 18 studies and demonstrated that B7-H4 was significantly associated with worse OS across cancer types. Cui et al [36] found that $\mathrm{B} 7-\mathrm{H} 4$ is predictive of poor prognosis in gastric cancer. These observations were in line with the results on NSCLC in the current meta-analysis. Notably, in the meta-analysis [37] exploring the impact of B7-H4 on prognosis of solid tumors, only one study [23] on NSCLC was included and NSCLC could not be analyzed separately. However, in the current analysis containing 9 studies on NSCLC, we analyzed the association between $\mathrm{B} 7-\mathrm{H} 4$ and clinicalpathological factors and survival outcomes. Therefore, this is the first meta-analysis on the relationship between B7-H4 expression and clinicalpathological features and OS in NSCLC patients. We noted included studies used various methods including immunohistochemistry (IHC), quantitative immunofluorescence (QIF), and enzyme linked immunosorbent assay (ELISA) to detect B7-H4 expression. Thus, the sensitivity of different methods may vary, resulting in inconsistent cut-offs in each study. This issue may lead to conflicting results and have potential impacts on this meta-analysis. Therefore, further studies with uniform detection method are needed.

There were also several limitations to this metaanalysis. First, although we searched literature both in English and Chinese, most included studies were conducted in China. Therefore, patient selection bias maybe exists. Second, the eligible studies for OS analysis were limited. Only 3 studies were included for the OS analysis. More large scale studies are needed for metaanalysis to make the conclusions more concrete.
In summary, despite the limitations listed above, this meta-analysis demonstrated that elevated B7-H4 expression was significantly associated with presence of lymph node metastasis, advanced TNM stage, poor differentiation and shorter OS in NSCLC. High B7-H4 expression is an unfavorable prognostic factor in NSCLC.

\section{MATERIALS AND METHODS}

\section{Search strategy}

We conducted this meta-analysis under the guideline of the Preferred Reporting Items for Systematic Reviews and Meta-Analyses (PRISMA) statement [39]. We performed a comprehensive literature search of the following databases: PubMed, Embase, Web of Science and China National Knowledge Infrastructure (CNKI). The last search was updated on November 10, 2016. The published languages were limited to English and Chinese. The searching items were: "B7-H4", "B7x", "B7S1", "lung cancer", "lung carcinoma", "lung neoplasm" and "lung tumor". The reference lists of the selected articles were searched to identify relevant studies.

\section{Selection criteria}

The inclusion criteria were as follows: (1) diagnosis of NSCLC was proven by histopathological methods; (2) B7-H4 was detected by any method; (3) studies reported the correlation of B7-H4 with clinicopathological factors or overall survival (OS); (4) when there were multiple 
studies on the same patients population, the largest or the most recent one was included; (5) articles were published in English or Chinese. The exclusion criteria were as follows: (1) meeting abstracts, reviews, letters, or case reports; (2) duplicated studies; (3) studies which lack necessary information.

\section{Data extraction and quality assessment}

Two investigators (ZBT and WXS) independently assessed the articles and extracted the following information form included studies: first author, publication year, study country, sample size, gender distribution, detection methods and tumor stage. The quality of each study was using the Newcastle-Ottawa Quality Assessment Scale (NOS)[40]. A study can be awarded a maximum of 9 points and studies obtained more than 6 were assigned as high quality studies (Table 3 ). Disagreements between the two investigators were resolved by consensus.

\section{Statistical analysis}

STATA 12 (StataCorp LP, College Station, TX, USA) was employed to conduct this meta-analysis. Odds ratios (ORs) and their 95\% confidence intervals (CIs) were used to estimate the association between B7-H4 expression and clinicopathological factors, including gender, age, histology, lymph node metastasis, TNM stage, and differentiation. Statistical heterogeneity across studies was assessed by using Cochran's $\mathrm{Q}$ and $I^{2}$ statistics. Heterogeneity was considered as statistically significant at $I^{2}>50 \%$ and $\mathrm{P}_{\mathrm{h}}<0.10$. In that case, the random effect model was used; otherwise, the fixed effect model was applied. Hazard ratios (HRs) and corresponding $95 \%$ CIs were pooled for the analysis of B7-H4 expression and OS. Begg's funnel plot was generated to examine potential publication bias. All statistical tests were two-sided, and a $\mathrm{P}$ value $<0.05$ was considered as statistically significant.

\section{CONFLICTS OF INTEREST}

The authors declare no conflicts of interest.

\section{REFERENCES}

1. Torre LA, Bray F, Siegel RL, Ferlay J, Lortet-Tieulent J, Jemal A. Global cancer statistics, 2012. CA Cancer J Clin. 2015; 65:87-108.

2. Alberg AJ, Brock MV, Ford JG, Samet JM, Spivack SD. Epidemiology of lung cancer: Diagnosis and management of lung cancer, 3rd ed: American College of Chest Physicians evidence-based clinical practice guidelines. Chest. 2013; 143:e1S-29S.

3. Parums DV. Current status of targeted therapy in non-small cell lung cancer. Drugs Today (Barc). 2014; 50:503-25.
4. Osarogiagbon RU. Predicting survival of patients with resectable non-small cell lung cancer: beyond TNM. J Thorac Dis. 2012; 4:214-16.

5. Hanahan D, Weinberg RA. Hallmarks of cancer: the next generation. Cell. 2011; 144:646-74.

6. Seliger B, Quandt D. The expression, function, and clinical relevance of B7 family members in cancer. Cancer Immunol Immunother. 2012; 61:1327-41.

7. Leung J, Suh WK. The CD28-B7 Family in Anti-Tumor Immunity: Emerging Concepts in Cancer Immunotherapy. Immune Netw. 2014; 14:265-76.

8. Chapoval AI, Ni J, Lau JS, Wilcox RA, Flies DB, Liu D, Dong H, Sica GL, Zhu G, Tamada K, Chen L. B7-H3: a costimulatory molecule for $\mathrm{T}$ cell activation and IFNgamma production. Nat Immunol. 2001; 2:269-74.

9. Suh WK, Wang S, Duncan GS, Miyazaki Y, Cates E, Walker T, Gajewska BU, Deenick E, Dawicki W, Okada $\mathrm{H}$, Wakeham A, Itie A, Watts TH, et al. Generation and characterization of B7-H4/B7S1/B7x-deficient mice. Mol Cell Biol. 2006; 26:6403-11.

10. Zhu G, Augustine MM, Azuma T, Luo L, Yao S, Anand S, Rietz AC, Huang J, Xu H, Flies AS, Flies SJ, Tamada K, Colonna M, et al. B7-H4-deficient mice display augmented neutrophil-mediated innate immunity. Blood. 2009; 113:1759-67.

11. Dong Q, Ma XL. B7-H4 Expression Is Associated with Tumor Progression and Prognosis in Patients with Osteosarcoma. Biomed Res Int. 2015. doi: $10.1155 / 2015 / 156432$.

12. Wu L, Deng WW, Yu GT, Mao L, Bu LL, Ma SR, Liu B, Zhang WF, Sun ZJ. B7-H4 expression indicates poor prognosis of oral squamous cell carcinoma. Cancer Immunol Immunother. 2016; 65:1035-45.

13. Yao Y, Ye H, Qi Z, Mo L, Yue Q, Baral A, Hoon DS, Vera JC, Heiss JD, Chen CC, Hua W, Zhang J, Jin K, et al. B7-H4(B7x)-Mediated Cross-talk between GliomaInitiating Cells and Macrophages via the IL6/JAK/STAT3 Pathway Lead to Poor Prognosis in Glioma Patients. Clin Cancer Res. 2016; 22:2778-90.

14. Zhang SA, Wu ZX, Zhang X, Zeng ZY, Li DL. Circulating B7-H4 in serum predicts prognosis in patients with hepatocellular carcinoma. Genet Mol Res. 2015; 14:13041-48.

15. Arigami T, Uenosono $Y$, Ishigami $S$, Hagihara $T$, Haraguchi $\mathrm{N}$, Natsugoe S. Clinical significance of the B7-H4 coregulatory molecule as a novel prognostic marker in gastric cancer. World J Surg. 2011; 35:2051-57.

16. Sun Y, Wang Y, Zhao J, Gu M, Giscombe R, Lefvert AK, Wang X. B7-H3 and B7-H4 expression in non-small-cell lung cancer. Lung Cancer. 2006; 53:143-51.

17. Zhang CD, Shi JP, Wang FM, Xu QL, Chen BH. Expression of negative costimulatroy molecule B7-H4 in non-small cell lung cancer tissues and its clinical significance. Zhongguo Zhongliu Shengwu Zhiliao Zazhi. 2009; 16:633-36. 
18. Qin XD, Ding W, Yao ZR, Lu HZ. Expression and clinical significance of B7-H4 in non small cell lung cancer. Shaanxi Medical Journal; 2010; 19-22.

19. Moudgil T, Puri S, Bifulco C, Urba WJ, Fox BA. Intracellular expression of the co-inhibitory molecule, B7-H4, in NSCLC cell lines: is it real? What does it do? J Immunother. 2012; 35:104.

20. Xu C, Qian L, Yu L, Zhang X, Wang Q. Evaluation of serum and pleural levels of soluble B7-H4 in lung cancer patients with pleural effusion. Biomarkers. 2015; 20:271-74.

21. Chen C, Zhu WD, Xie F, Huang JA. Nuclear localization of B7-H4 in pulmonary adenocarcinomas presenting as a solitary pulmonary nodule. Oncotarget. 2016; 7:58563-68. doi: 10.18632/oncotarget.10542.

22. Xu YH, EWang JM, Zhang GB, Hu HC. Expression and clinical significance of CD133 and B7-H4 in non small cell lung cancer. Jiangsu Med J. 2011; 412-415 368372.

23. Li ZY, Zhang XH, Chen Y, Guo JG, Sai K, Yang QY, Chen ZP, Mou YG. Clinical significance of B7-H4 expression in matched non-small cell lung cancer brain metastases and primary tumors. Onco Targets Ther. 2013; 6:869-75.

24. Liu AH, Chen XK. Expression and clinical significance of $\mathrm{CO}$ signaling molecule $\mathrm{B} 7-\mathrm{H} 4$ in human lung adenocarcinoma. Journal of Clinical Pulmonary Medicine. 2015; 1791-1793.

25. Schalper KA, Carvajal-Hausdorf D, McLaughlin J, Altan M, Velcheti V, Gaule P, Sanmamed MF, Chen L, Herbst RS, Rimm DL. Differential expression and significance of PD-L1, IDO-1 and B7-H4 in human lung cancer. Clin Cancer Res. 2016. doi: 10.1158/1078-0432.CCR-16-0150.

26. Wang W, Xu C, Wang Y, Yu L, Zhang X. Prognostic values of B7-H4 in non-small cell lung cancer. Biomarkers. 2016:1-16.

27. Xu CH, Wang W, Wang YC, Lin Y, Zhang XW. Diagnosis value of serum soluble B7-H4 expression in non-small cell lung cancer. Clin Respir J. 2016; doi: 10.1111/crj.12499.

28. Sica GL, Choi IH, Zhu G, Tamada K, Wang SD, Tamura H, Chapoval AI, Flies DB, Bajorath J, Chen L. B7-H4, a molecule of the $\mathrm{B} 7$ family, negatively regulates $\mathrm{T}$ cell immunity. Immunity. 2003; 18:849-61.

29. Wang X, Wang T, Xu M, Xiao L, Luo Y, Huang W, Zhang Y, Geng W. B7-H4 overexpression impairs the immune response of $\mathrm{T}$ cells in human cervical carcinomas. Hum Immunol. 2014; 75:1203-09.
30. Zhao LW, Li C, Zhang RL, Xue HG, Zhang FX, Zhang F, Gai XD. B7-H1 and B7-H4 expression in colorectal carcinoma: correlation with tumor FOXP3 $(+)$ regulatory T-cell infiltration. Acta Histochem. 2014; 116:1163-68.

31. Kryczek I, Wei S, Zou L, Zhu G, Mottram P, Xu H, Chen L, Zou W. Cutting edge: induction of B7-H4 on APCs through IL-10: novel suppressive mode for regulatory T cells. J Immunol. 2006; 177:40-44.

32. Shi H, Ji M, Wu J, Zhou Q, Li X, Li Z, Zheng X, Xu B, Zhao W, Wu C, Jiang J. Serum B7-H4 expression is a significant prognostic indicator for patients with gastric cancer. World J Surg Oncol. 2014; 12:188.

33. Xu Y, Zhu S, Song M, Liu W, Liu C, Li Y, Wang M. B7-H4 expression and its role in interleukin-2/interferon treatment of clear cell renal cell carcinoma. Oncol Lett. 2014; 7:1474-78.

34. Chen Y, Sun J, Zhao H, Zhu D, Zhi Q, Song S, Zhang L, He S, Kuang Y, Zhang Z, Li D. The coexpression and clinical significance of costimulatory molecules B7-H1, B7-H3, and B7-H4 in human pancreatic cancer. Onco Targets Ther. 2014; 7:1465-72.

35. Zang X, Thompson RH, Al-Ahmadie HA, Serio AM, Reuter VE, Eastham JA, Scardino PT, Sharma P, Allison JP. B7-H3 and $\mathrm{B} 7 \mathrm{x}$ are highly expressed in human prostate cancer and associated with disease spread and poor outcome. Proc Natl Acad Sci USA. 2007; 104:19458-63.

36. Cui Y, Li Z. B7-H4 is Predictive of Poor Prognosis in Patients with Gastric Cancer. Med Sci Monit. 2016; 22:4233-37.

37. Song X, Shao Y, Gu W, Xu C, Mao H, Pei H, Jiang J. Prognostic role of high B7-H4 expression in patients with solid tumors: a meta-analysis. Oncotarget. 2016; 7:76523-33. doi: 10.18632/oncotarget.8598.

38. Zhu Q, Xiong H, Azimu S, Abudureyimu A. Expression of B7-H4 and gastric cancer progression and prognosis: a meta-analysis. Int J Clin Exp Med. 2016; 9:15185-90.

39. Moher D, Liberati A, Tetzlaff J, Altman DG. Preferred reporting items for systematic reviews and metaanalyses: the PRISMA statement. Ann Intern Med. 2009; 151:264-269, w264.

40. Stang A. Critical evaluation of the Newcastle-Ottawa scale for the assessment of the quality of nonrandomized studies in meta-analyses. Eur J Epidemiol. 2010; 25:603-05. 